Conference abstract PDD10

\title{
The Study of Flowing Properties of Hydrogels
}

\section{P. HerdovÁ, Z. VitKovÁ}

Faculty of Pharmacy, Commenius University, Bratislava, Slovakia

E-mail: herdova@fpharm.uniba.sk (P. Herdová)

Sci Pharm. 2010; 78: 599

doi:10.3797/scipharm.cespt.8.PDD10

The topic of this article was to monitor the impact of excipients on viscosity of gels with local anaesthetic. In previous studies the optimal excipients from the group of polymers, enhancers and humectants were examinated during the formulation of chlorhexidine, trimecain and terbinafine to the medical form - hydrogel $[1,2]$. The choice of gel creating compound is influencing the reological properties of drug as directly affects its consistency. Reological properties - viscosity - are very important at dermal semisolid drugs, mainly at gels from the aspect of their use. The manufacturing process is significantly influencing the gels consistency as well.

The reological properties were evaluated in the study of hydrogels prepared from various gel creatig compounds (Natrosol $250 \mathrm{HX}$, Natrosol $250 \mathrm{HHX}$, Natrosol 250 $\mathrm{HR}$ and Chitosan) with active ingredient of trimecaini hydrochloridum and gels without the active ingredient. Then the influence of propylenglycol and glycerol humectants in various concentrations on Mesocain gel were examinated. Solitary influence of excipients was evaluated using the analyses of reological measurement results.

This work was supported by the Grant VEGA No. 1/ 0320/ 08

[1] Vitková Z, Herdová P, Šubová M, Šimunková V. [Formulation of chlorhexidin into gels]. Ceska Slov Farm. 2009; 58: 116-118.

[2] Herdová P, Vitková Z, Čižmárik J. [Study of local anaesthetics: Part 189. Evaluation of flowing attributes of drug Mesocain gel by using different gel- creating compounds]. Farm Obz. 2009; 78: 151153. 